\title{
National Presentation of the United States of America
}

\author{
Rick Scott
}

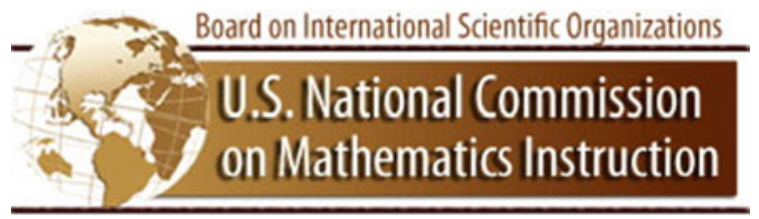

The United States of America was honored to be invited to make one of the National Presentations at the 12th International Congress on Mathematical Education in Seoul, Korea. The United States National Commission on Mathematics Instruction (USMC/MI) oversaw the U.S. participation. (The USNC/MI advises the National Academy of Sciences-National Research Council (NAS-NRC) in all matters pertaining to the International Commission on Mathematical Instruction.) Significant financial support was supplied by the National Science Foundation (NSF) and important logistical support was provided by the National Council of Teachers of Mathematics (NCTM). The main activities of the U.S.A. National Presentation were the

- National Presentation sessions,

- U.S.A. Exhibit,

- Capsule Summary Fact Book, and

- U.S.A. Reception.

\section{The National Presentation Sessions}

The National Presentation highlighted the uniqueness and important features of mathematics education in the U.S. in two 90-min sessions with a total of five presentations. The first three presentations provided An Overview of Math Ed in the

\footnotetext{
R. Scott $(\bowtie)$

U.S. National Commission on Mathematics Instruction, Washington DC, USA

e-mail: pscott@nmsu.edu

(C) The Author(s) 2015

S.J. Cho (ed.), The Proceedings of the 12th International Congress

on Mathematical Education, DOI 10.1007/978-3-319-12688-3_22
} 
U.S.: Curriculum Reform. The last two focused on Teaching Mathematics in the United States.

1. Mathematics Education in the United States 2012-Katherine Halvorsen, Smith College

This presentation provided an overview on the system of education in the U.S., including the size of the educational enterprise, governance, intended curriculum, implemented curriculum, attained curriculum, the Common Core Standards in Mathematics (CCSSM), programs for special populations, and teacher education and professional development. More details can be found below in the section entitled A Capsule Summary Fact Book.

2. Evolution and Revolution: From the NCTM Standards to the Common Core State Standards in the U.S.-Michael Shaughnessy, Immediate Past President of the National Council of Teachers of Mathematics (NCTM)

This short history on mathematics standards in the U.S. pointed to the main NCTM documents and the major themes in those documents (1989 and 2000 NCTM Standards, Curriculum Focal Points, and the high school Reasoning and Sense Making Initiative). The case was made that the CCSSM represents an evolutionary step, anchored in NCTM's Process Standards and the Adding It Up proficiencies, drew on Curriculum Focal Points series, and is closely tied to NCTM's Reasoning and Sense Making effort. The revolutionary step is that the CCSSM is common. The history of prior adoption and implementation mathematics standards in the US has been on a state by state basis, with local control and local decision making. For states to adopt a set of Common Standards is quite different for our nation.

3. Research Perspectives on Mathematics Standards Reform in the U.S.-Mary Kay Stein, University of Pittsburgh

The presentation began with a short introduction that identified the roles that research can and has played in past standards-based eras. Then attention turned to some key areas in which research might shed light in this era of the CCSSM. After referring to the NSF report, A Priority Research Agenda for Understanding the Influence of the CCSSM, four features of the CCSSM were outlined that set them apart from past standards: Fewer, clearer, higher standards; learning progressions; the positioning of mathematical practices, and their commonness. Theories-of-action associated with how each of these features is expected to contribute to improved mathematics instruction and student learning were described. Suggestions were made regarding how research could help us monitor the extent to which the theories-of-action play out as expected and whether there are any unintended consequences.

4. The "Mathematics Studio": Sustainable School-Based Professional LearningLinda Foreman, President of Teachers Development Group

The design of the "Mathematics Studio" professional development model is guided by a robust body of research on effective mathematics learning, teaching, professional development, and school leadership. Implementation of the model over time produces a powerful school-based culture of professional learning in 
which sense making about meaningful mathematics instruction is continuous for all teachers and school leaders. At the heart of this work is engaging all mathematics teachers and leaders from a school together-during live classroom teaching episodes - in publicly coached rehearsals of well-defined, researchbased "mathematically productive teaching routines." Grounded by the premise that all students are capable mathematical thinkers, this work fosters leaders' and teachers' habitual use of practices that yield all students' internalization of mathematical habits of mind typified by the Common Core State Standards for Mathematical Practice. This presentation provided a glimpse of the Mathematics Studio model's design, implementation, and impact.

5. Challenges of Knowing Mathematics for Teaching in the United StatesDeborah Ball, University of Michigan

Teachers' mathematical knowledge is a concern in many countries around the world. However, several features of the U.S. educational context present special challenges for ensuring that teachers know mathematics well enough to teach it. This presentation examined the mathematical knowledge needed for teaching and analyzed the special challenges presented by the U.S. context. Questions for participants were: How unique are these U.S. challenges for mathematical knowledge for teaching? Do other countries share these challenges?

\section{The U.S.A. Exhibit}

The U.S. Exhibit showcased not only the uniqueness of math education in the U.S., but also the diversity and variety of products, key players, and stakeholders involved in the practice. The U.S. exhibit included speakers, videos, materials, and interactive experiences.

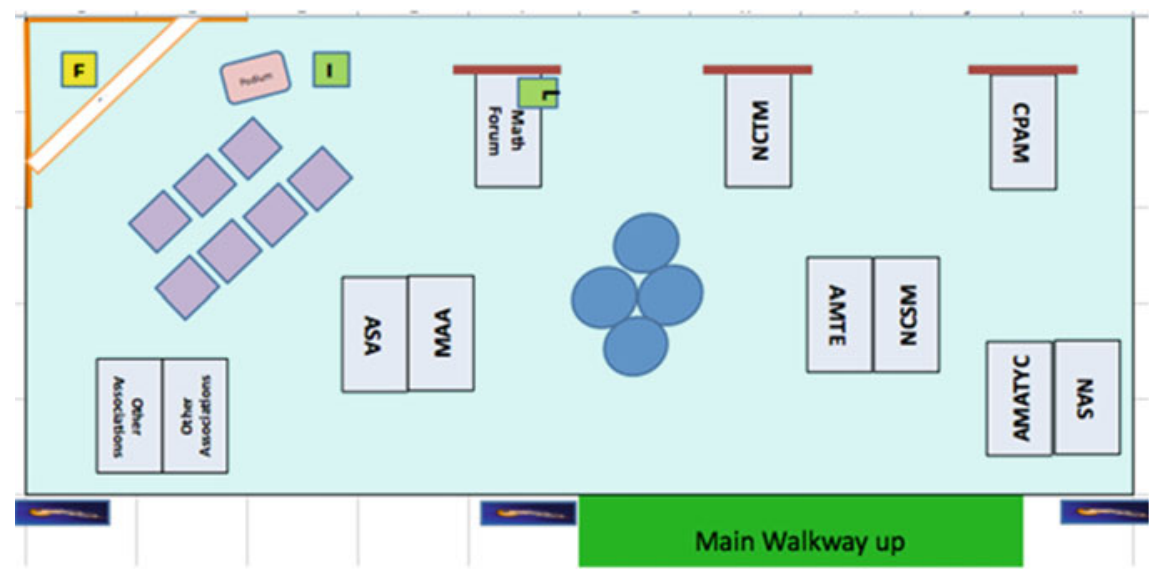


Since the number and diversity of the professional organizations devoted to various aspects of mathematics education was judged to be something unique about the United States all such organizations were asked to exhibit information about their activities. The figure on the right, which was one of the banners at the entrance to the Exhibit, indicates the organizations that participated in the U.S.A. National Exhibit.

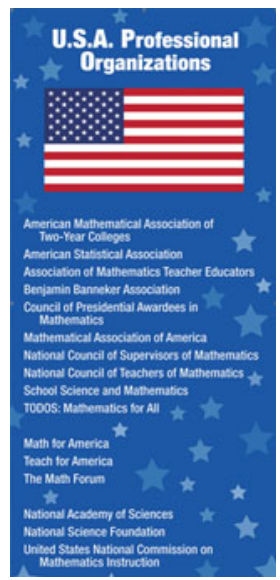

A unique aspect of the Exhibit was that a corner was set aside with a projector and a screen so that presentations could be made. Those presentations led to many productive international conversations.

Another corner of the Exhibit area had a monitor that showed videos of mathematics classes in the United States. Coordinated by the Council of Presidential Awardees in Mathematics (http://cpam.teachersdg.org/), participants were assisted in using an iPad app called "Common Core Look-fors (CCL4s)" that can be used as a non-evaluative assessment tool to determine the extent to which teachers and students are engaged in aspects of the Common Core Mathematical Practices (http://www.corestandards.org/). Both an English transcription and a translation of the transcription into Korean were provided for the video clips. Those transcriptions helped many visitors understands the clips and use the iPad app.

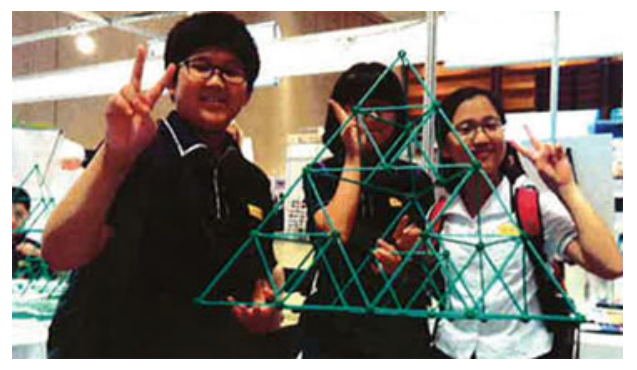


Particularly popular among both teachers and the crowds of Korean students who attended ICME-12 were Zome Tools (http://zometool.com/), an innovative manipulative that challenges students to creatively explore geometry and informally introduces them to concepts of topology. In addition to working at the tables set up in the middle of the exhibit, teachers and students were given individual packets of Zome Tools so they could continue with their explorations.

Besides USNC/MI members and representatives from the professional organizations in the Exhibit, U.S. mathematics educators who had received travel grants from NCTM with funding from the National Science Foundation (NSF) also took turns at the Exhibit discussing mathematics educations with visitors to the Exhibit.

\section{A Capsule Summary Fact Book}

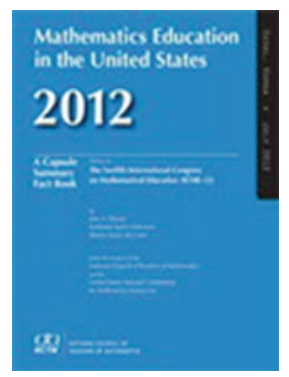

It has become a tradition for NCTM to commission for each ICME a document entitled Mathematics Education in the United States: A Capsule Summary Fact Book. For ICME-12 it was prepared by John Dossey, Katherine Halvorsen, and Sharon McCrone. Attendees at the National Presentation and the National Exhibit were given a copy of the Fact Book on a USB drive. The following two paragraphs from the "Preface" give a very good indication of what can be found in the complete report:

This document begins with some general information about education in the United States. The three kinds of curricula identified in the Second International Mathematics Studyintended, implemented, and attained — are then described (McKnight et al. 1987). A special focus is given to the emergence of a common $\mathrm{K}$-grade 12 curriculum that has been adopted by forty-five states and the District of Columbia. This curriculum, the Common Core State Standards for Mathematics (CCSSM), was developed by a consortium consisting of state governors and chief state education officers (National Governors Association Center for Best Practices and Council of Chief State School Officers [NGA Center and CCSSO] 2010). The adoption of such a set of common outcomes, matching assessments, and similar instructional materials is expected to bring to U.S. mathematics education a level of uniformity that it has never before seen. 
As in earlier editions, this publication has sections dealing with programs for highachieving students, programs for mathematics teacher education, and resources for additional information about U.S. mathematics education. One message that comes through repeatedly in these descriptions is the variety of available programs and thus the inability to characterize them adequately in a brief document like this one. Another message is that all levels of the educational system exhibit great flux, and even though we have attempted to provide the latest available information, we realize that the information presented here will quickly become dated. By listing our sources, we hope to enable the interested reader to obtain updated information.

The report is available for download at www.nctm.org/about/affiliates/content. aspx?id=16955.

\section{The U.S. Reception}

A U.S. reception was held at the ICME-12 on July 10th for 150 international attendees. The reception was intended to foster international collaborations between U.S. math educators and their international peers. A Speed Networking session facilitated the networking experience between the attendees. The reception was

\section{$\left(x^{2}\right)$
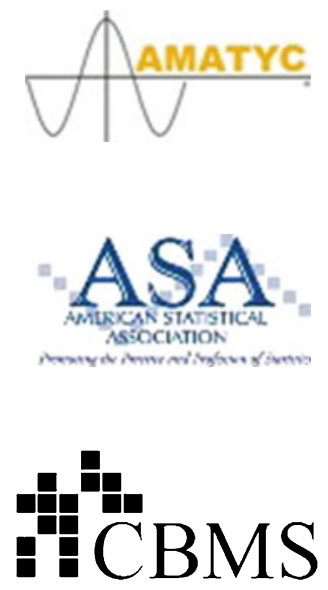
sponsored by the National Council of Teachers of Mathematics (NCTM), the American Mathematical Association of Two-Year Colleges (AMATYC), The American Statistical Association (ASA), and the Conference Board of the Mathematical Sciences (CBMS).

Open Access This chapter is distributed under the terms of the Creative Commons Attribution Noncommercial License, which permits any noncommercial use, distribution, and reproduction in any medium, provided the original author(s) and source are credited. 